\author{
S. GHOSH ${ }^{1, \infty}$ \\ P. SRIVASTAVA ${ }^{1}$ \\ B. PANDEY ${ }^{1}$ \\ M. SAURAV ${ }^{1}$ \\ P. BHARADWAJ ${ }^{1}$ \\ D.K. AVASTHI ${ }^{2}$ \\ D. KABIRAJ ${ }^{2}$ \\ S.M. SHIVAPRASAD 3
}

\section{Study of $\mathrm{ZnO}$ and Ni-doped $\mathrm{ZnO}$ synthesized by atom beam sputtering technique}

\author{
${ }^{1}$ Nanostech Laboratory, Department of Physics, Indian Institute of Technology Delhi, Hauz Khas, \\ New Delhi 110016, India \\ 2 Inter University Accelerator Centre, Aruna Asaf Ali Marg, New Delhi 110067, India \\ ${ }^{3}$ National Physical Laboratory, Dr. K.S. Krishnan Marg, New Delhi 110012, India
}

\begin{abstract}
Received: 13 May 2007/Accepted: 31 October 2007
Published online: 8 December 2007 • () Springer-Verlag 2007

ABSTRACT Zinc oxide $(\mathrm{ZnO})$ and $\mathrm{Ni}$-doped zinc oxide ( $\mathrm{ZnO}: \mathrm{Ni})$ films are prepared by atom beam sputtering with an intent of growing transparent conducting oxide (TCO) material and understanding its physical properties. The crystalline phases of the films are identified by the grazing angle $\mathrm{X}$-ray diffraction (GAXRD) technique. Thicknesses of the films are measured by ellipsometry. Chemical states of the elements present in the films are investigated by X-ray photoelectron spectroscopy (XPS), which indicates the presence of $\mathrm{Ni}$ in the $\mathrm{ZnO}$ environment in a divalent state. Average transmission across the $\mathrm{ZnO}: \mathrm{Ni}$ film was determined to be $\sim 83 \%$ in the visible region, which is less than that $(\sim 90 \%)$ of undoped $\mathrm{ZnO}$ films. The resistivity measured by van der Pauw technique of the $\mathrm{ZnO}: \mathrm{Ni}$ film $\left(\sim 9 \times 10^{-3} \Omega \mathrm{cm}\right)$ is two orders of magnitude smaller as compared to its undoped counterpart $(1 \Omega \mathrm{cm})$. For $\mathrm{ZnO}: \mathrm{Ni}$ film an average carrier concentration of $\sim 1.4 \times 10^{19} \mathrm{~cm}^{-3}$ was observed by Hall measurements. Two important mechanisms reported in the literature viz. influence of $d-d$ transition bands and electron scattering from crystallites/grains are discussed as the possible causes for the increase in conductivity on $\mathrm{Ni}$ doping in $\mathrm{ZnO}$.
\end{abstract}

PACS 73.50.Bk; 78.66.Li; 79.60.Dp; 61.05.cp

\section{$1 \quad$ Introduction}

Zinc oxide $(\mathrm{ZnO})$, due to its specific electrical, optical and mechanical properties is one of the important wide band gap semiconductor materials. There is growing interest in $\mathrm{ZnO}$ due to its potential applicability in optoelectronic devices, such as light-emitting diodes, laser diodes and detectors for UV wavelength range. Properties of $\mathrm{ZnO}$ are very close to those of the widely recognized semiconductor, $\mathrm{GaN}$. The band gap of $\mathrm{ZnO}(3.37 \mathrm{eV})$ is close to that of $\mathrm{GaN}$ $(3.39 \mathrm{eV})$, but $\mathrm{ZnO}$ exciton binding energy $(60 \mathrm{meV})$ is approximately two times larger than that of $\mathrm{GaN}(28 \mathrm{meV})$ [1], which makes it more promising as an optoelectronic material. The importance of metal-doped $\mathrm{ZnO}$ as TCO material has been discussed by different groups in the recent past [2-6]. Several reports on $\mathrm{ZnO}$ doped with $\mathrm{Al}, \mathrm{Ga}$, In, etc.

Fax: +91-11-26581114, E-mail: ghoshsantanu1@yahoo.co.in describing their optical, structural and electrical characteristics have been published recently [2-6]. It is also mentioned that doped $\mathrm{ZnO}$ can be prepared as a less expensive TCO material [7]. Important results of the above mentioned studies are: (i) Al-doped $\mathrm{ZnO}$ having transmittance $\sim 88 \%$ and resistivity approximately $8.5 \times 10^{-5} \Omega \mathrm{cm}$ [5]; (ii) nanocrystalline $\mathrm{ZnO}$ :Ga films having resistivity $7 \times 10^{-4} \Omega \mathrm{cm}$ and average transparency $\sim 93 \%$ [3]; (iii) synthesis of a p-type $\mathrm{ZnO}$ [4].

In earlier studies, doping of $\mathrm{ZnO}$ by transition metal elements was usually not tried, probably due to the incompatibility in the electron affinity or ionic radii of such elements with that of $\mathrm{Zn}$. Of late, the motivation of making spintronic devices based on diluted magnetic semiconductors led the researchers to dope $\mathrm{ZnO}$ with $\mathrm{Fe}, \mathrm{Co}, \mathrm{Ni}, \mathrm{Mn}$ etc. There are promising results in this area [8-10] and above room temperature ferromagnetism was realized in $\mathrm{ZnO}$ :Ni film recently $[9,10]$.

Doping of $\mathrm{Ni}$ in $\mathrm{ZnO}$ matrix has been done by several techniques [10-12], however, effect on resistivity of $\mathrm{ZnO}$ on Ni doping is not well established so far. Films grown by rf magnetron sputtering were found to be insulating up to a Ni concentration of $20 \%$ [11]. The Ni-doped ( 2 mol \%) $\mathrm{ZnO}$ films prepared by spin coating showed a resistivity of $1.4 \times 10^{-1} \Omega \mathrm{cm}$ [13]. Singh et al. [14] have reported decrease in resistivity up to $2 \mathrm{~mol} \%$ of $\mathrm{Ni}$ doping in bulk $\mathrm{ZnO}$ samples. Moreover, in a very recent communication, Wang et al. reported enhancement of resistivity in Ni-doped $\mathrm{ZnO}$ deposited by magnetron sputtering technique [12].

The present work is motivated to find a synthesis process for growing Ni-doped $\mathrm{ZnO}$ as transparent conducting oxide i.e., to enhance the electrical conductivity of the film, retaining of course optical transmission in the visible range to a high value. This kind of study may open up the possibility of synthesizing transition metal-doped transparent conducting oxide apart from their important usage as magnetic semiconductor material. Here we are reporting for the first time the synthesis of $\mathrm{Ni}$-doped $\mathrm{ZnO}$ thin films grown by atom beam sputtering technique and a study of their transparent conducting properties.

\section{$2 \quad$ Experimental details}

A set of transparent films were grown on silicon and quartz substrates. For atom beam sputtering, an Ar atom gun source was mounted at $45^{\circ}$ facing towards the sputter- 
ing target (4 $\mathrm{N} \mathrm{ZnO}$ disc of 2 inch diameter). The cleaned substrates were mounted at a variable gap below the target. The base pressure obtained in the chamber was $7 \times 10^{-7}$ mbar with a turbo molecular-rotary pump combination. Deposition pressure was $2.6 \times 10^{-3}$ mbar. The source delivered $\sim 13 \mathrm{~mA}$ current on the target, with energy of $\sim 1 \mathrm{keV}$. The area of the Ar beam was approximately $50 \mathrm{~mm}$ in diameter at the source. The $\mathrm{ZnO}$ disc is sputtered by $\mathrm{Ar}$ atom beam and $\mathrm{ZnO}$ films were deposited on the substrates. The time of deposition for both these films was $8 \mathrm{~h}$. For deposition of $\mathrm{ZnO}: \mathrm{Ni}$ films, $\mathrm{Ni}$ foils were glued to the $\mathrm{ZnO}$ disc and co-sputtered by the Ar beam. Crystalline phases of the films were identified by grazing angle X-ray diffraction technique with $\mathrm{Cu} K_{\alpha}$ radiation in Bragg-Brantano geometry [15], and the crystallite size along $z$-direction was determined with the help of the Scherrer formula [16]. Thickness of the films deposited on $\mathrm{Si}$ substrate was determined to be $80 \mathrm{~nm}$ by ellipsometry. The presence of Ni was confirmed by X-ray fluorescence using a PHILIPS (MINIPAL) system. To identify the chemical states of the elements present in the film, X-ray photoelectron spectroscopy (XPS) measurements were carried out using $\operatorname{Mg} K_{\alpha}$ radiation $(h v=1253.3 \mathrm{eV})$. The base pressure during the measurement was $5 \times 10^{-10}$ Torr. The $\mathrm{C}$ $1 s$ peak at $284.6 \mathrm{eV}$ was used as a reference to take care of the shifts due to charging effect. All measurements were carried out at room temperature after sputtering the films for 3 min with Ar ions of $4 \mathrm{kV}$. The pressure during sputtering was $1 \times 10^{-6}$ Torr. The resistivity and carrier concentration were measured in van der Pauw geometry. The measurements were carried out on a number of films deposited in the same batch and average values are reported in the next section. The optical transmittance measurement of these films was carried out with a HITACHI UV-VIS spectrometer.

\section{$3 \quad$ Results and discussion}

The calculation of film stoichiometry $(\mathrm{Ni} / \mathrm{ZnO})$ and results obtained from different characterization techniques are discussed in the following subsections.

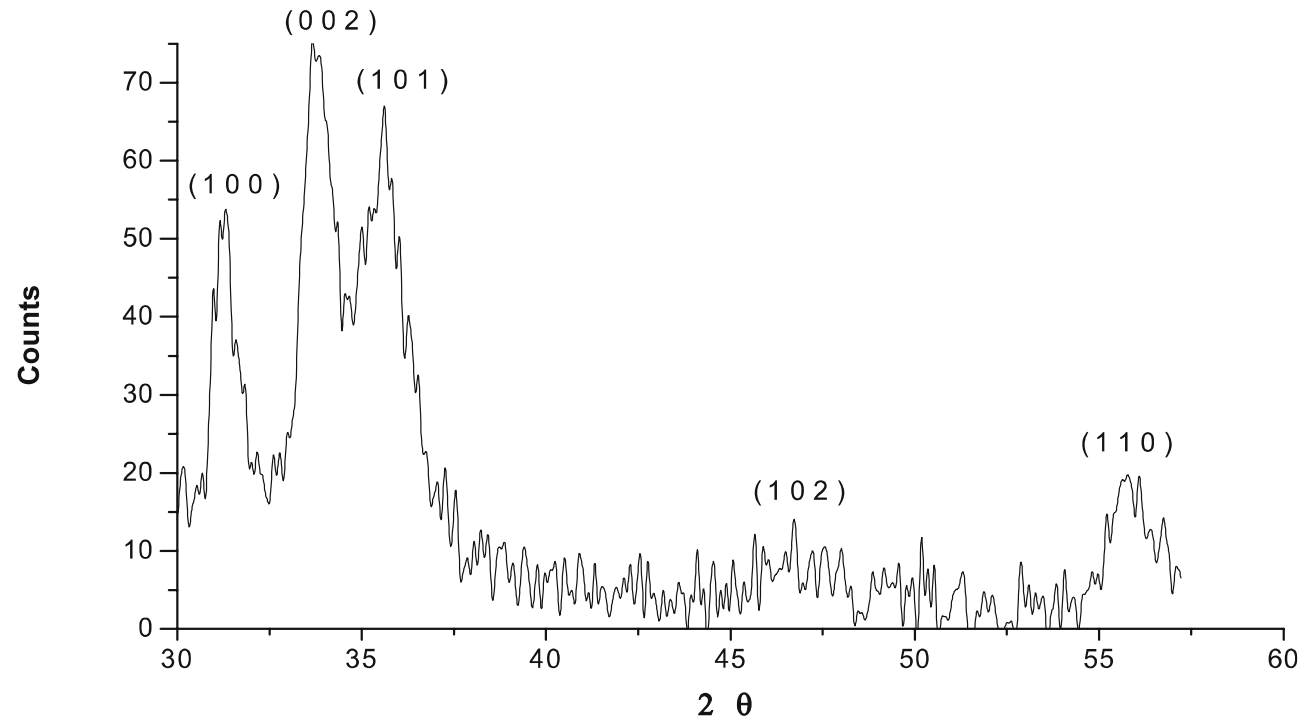

FIGURE 1 A typical glancing angle $\mathrm{X}$-ray diffraction pattern of $\mathrm{ZnO}: \mathrm{Ni} /$ quartz film. Similar spectrum was obtained for the film deposited on silicon substrate 


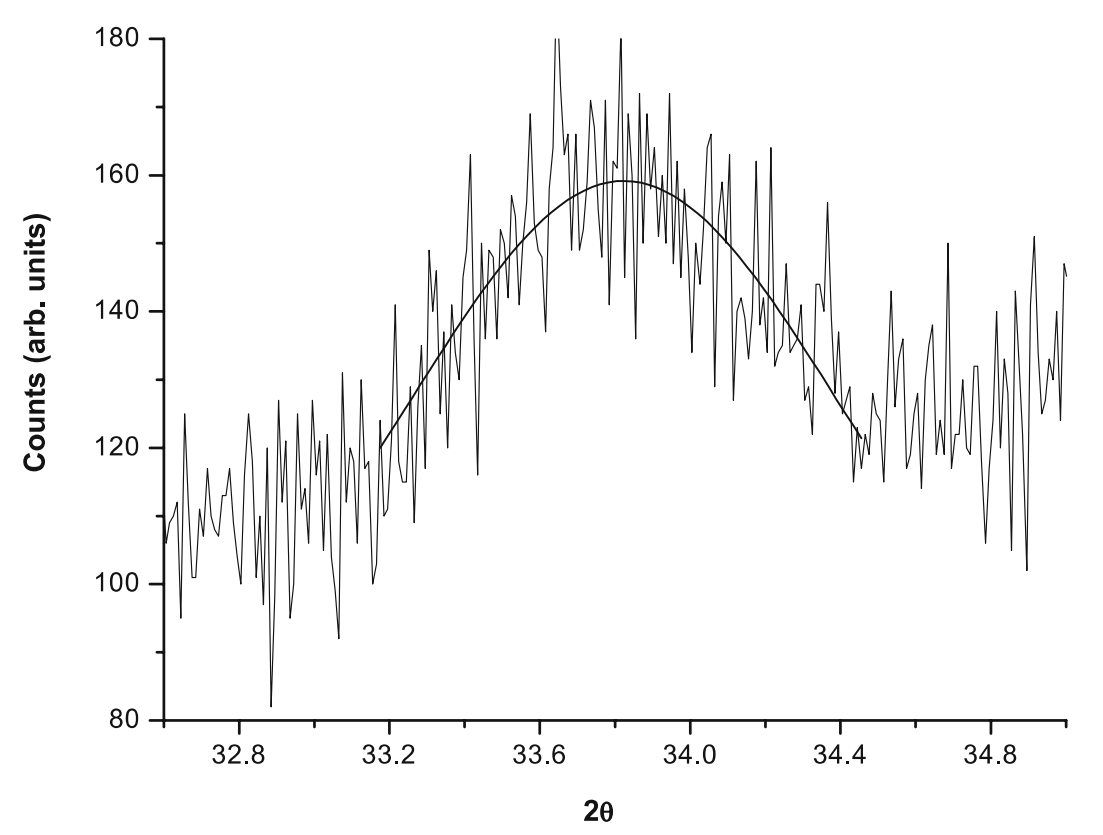

FIGURE 2 Gaussian fit of the peak corresponding to 002 plane of $\mathrm{ZnO}: \mathrm{Ni} /$ quartz film is shown for the determination of crystallite size

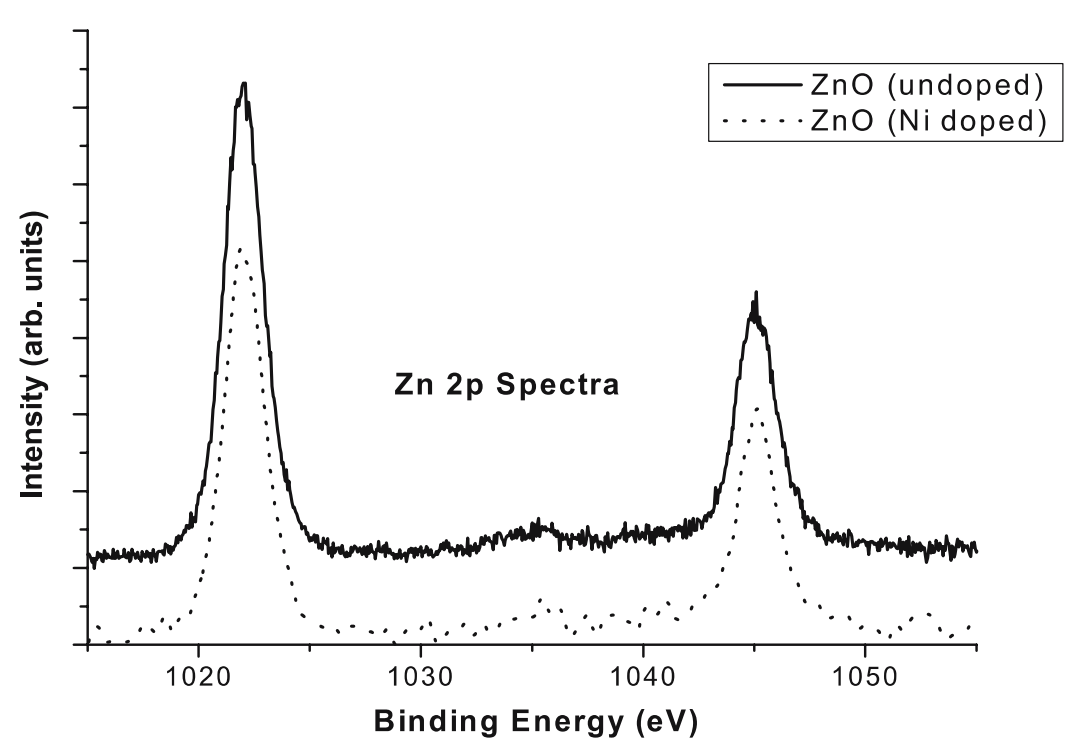

FIGURE 3 Zn $2 p$ core level XPS spectra of pure and Ni-doped $\mathrm{ZnO}$ film. No changes were observed in the spectrum on Ni doping

With the help of the Scherrer formula, the average crystallite size is found to be $\sim 3 \mathrm{~nm}$ and $\sim 10 \mathrm{~nm}$ for pure and $\mathrm{Ni}$-doped $\mathrm{ZnO}$ films, respectively.

\subsection{XPS measurements}

The chemical states of the elements present are discussed on the basis of XPS measurement. Figure 3 shows Zn $2 p$ spectra of both the films. The spectrum does not show any significant change on Ni doping. Figure 4 shows Ni $2 p_{3 / 2}$ peak of the Ni-doped $\mathrm{ZnO}$ film. It shows a clear satellite structure around $860 \mathrm{eV}$. Similar satellite peaks were observed for nickel oxides previously and is ascribed to $\mathrm{O}(2 p) \rightarrow \mathrm{Ni}(3 d)$ charge-transfer transition or hybridization $[18,19]$. The presence of the satellite peak in Ni-doped $\mathrm{ZnO}$ films indicates that nickel is present in an oxygen environment in the film. $\mathrm{Ni}$ may be incorporated in the $\mathrm{ZnO}$ crystallite as interstitial or substitutional impurities. However, the binding energy pos- ition $(\sim 854 \mathrm{eV})$ of $\mathrm{Ni} 2 p_{3 / 2}$ is quite close to the one reported for $\mathrm{NiO}$ [20]. Therefore, present XPS measurements strongly suggest that in the doped films $\mathrm{Ni}^{2+}$ ions partly substitute $\mathrm{Zn}$ in the $\mathrm{ZnO}$ matrix and rule out the presence of $\mathrm{Ni}$ in metallic or +3 states.

3.4

\section{Optical characterization}

Figure 5 shows transmittance versus wavelength curves for both pure and Ni-doped $\mathrm{ZnO}$ films. These measurements were carried out on the films, which were deposited on quartz substrates. The figure shows that in the wavelength range between $400-800 \mathrm{~nm}$, the pure $\mathrm{ZnO}$ film has a transmission of $\sim 90 \%$. Though, doping of Ni slightly reduces the transmission, there is not much change $(\sim 7 \%)$ in maximum transmission value. A small blue shift is observed suggesting an increase in band gap values on doping. The observed results in enhancement of band gap can be attributed to the 

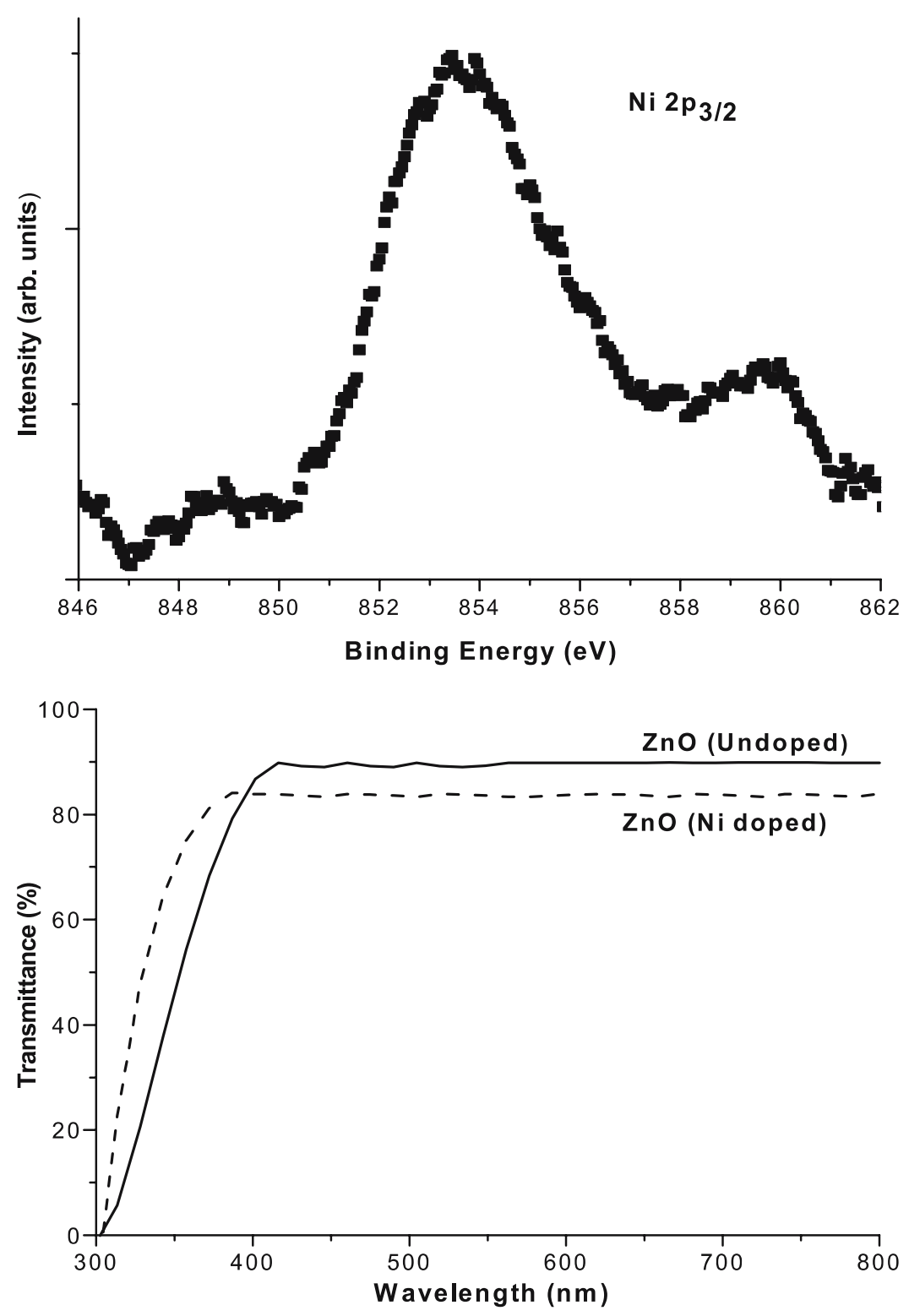

FIGURE $4 \mathrm{Ni} 2 p_{3 / 2}$ core level XPS spectrum of Nidoped $\mathrm{ZnO}$ film. A satellite structure close to $860 \mathrm{eV}$ can be seen clearly
FIGURE 5 Transmittance versus wavelength of $\mathrm{ZnO} /$ quartz and $\mathrm{ZnO}: \mathrm{Ni}$ /quartz films. A small blue shift is observed on Ni doping
Burstein-Moss effect $[2,21]$. We will come back to this point while discussing the conduction mechanism.

\subsection{Transport properties}

The resistivity measurement shows a significant decrease (more than two orders) of the resistivity value in $\mathrm{ZnO}: \mathrm{Ni}$ as compared to undoped $\mathrm{ZnO}$ film. The pure $\mathrm{ZnO}$ has a resistivity of $\sim 1 \Omega \mathrm{cm}$ whereas for the Ni-doped film the value is $9 \times 10^{-3} \Omega \mathrm{cm}$. To have a better understanding of the decrease in resistivity, Hall measurements were carried out at room temperature. The carrier concentration in the Ni-doped $\mathrm{ZnO}$ film was found to be $1.4 \times 10^{19} \mathrm{~cm}^{-3}$, which is in fair agreement with the reported one [8]. The film shows n-type conduction.

The reason for the decrease in resistivity on Ni doping is not very well understood. However, the present XPS measurements rule out the presence of $\mathrm{Ni}^{3+}$, cited as the reason for decrease in resistivity at low doping concentrations [8].
Also, no indication of metallic Ni was found that may decrease resistivity.

The $a b$ initio electronic structure calculations report existence of half metallic behavior in $\mathrm{V}, \mathrm{Cr}, \mathrm{Fe}, \mathrm{Co}$ and Ni-doped $\mathrm{ZnO}$ [20]. The electronic band calculations carried out within the frame work of local density approximation (LDA) suggest the $E_{\mathrm{F}}$ 's of $\mathrm{ZnO}: \mathrm{Fe}, \mathrm{Co}, \mathrm{Ni}$ are located near the top of the valence band and partial density of states (PDOS) values of $\mathrm{Fe}, \mathrm{Co}$ and $\mathrm{Ni}$ at $E_{\mathrm{F}}$ are relatively large [21]. As pointed out by Singh et al. [14], the $\mathrm{Ni} d$-states appearing near the $E_{\mathrm{F}}$ may be split into $e_{g}$ and $t_{2 g}$ states under the influence of tetrahedral crystal field of $\mathrm{ZnO}$. The $t_{2 g}$ state on hybridization with $p$ orbitals of the valence band further splits into bonding and anti-bonding states. The anti-bonding states having higher energies and itinerant electrons lie very close to the bottom of the conduction band (CB). The presence of itinerant electrons gives rise to increase in conductivity. In our case, these anti-bonding states seem to have merged with the CB as we observe not only an increase in electrical conductivity 
on Ni doping but also a slight increase in optical band gap. However, since the DOS close to the $E_{\mathrm{F}}$ are also quite sensitive to oxygen derived states, a detailed and careful study such as valence band photoemission is required on these films to substantiate/refute aforementioned arguments.

Other mechanism that can affect electron transport in the polycrystalline TCO films is scattering from crystallites or grains [3]. Grain boundaries, across which crystal orientations change, are expected to be effective electron scatterer and behave like film interfaces. For smaller crystallite size contribution to film resistivity from this scattering is large. In the present case as the crystallite size is larger in $\mathrm{ZnO}: \mathrm{Ni}$ film as compared to $\mathrm{ZnO}$ film and hence the probability of this scattering is less than in the former leading to a decrease in resistivity value.

As mentioned earlier, further studies are required to completely understand the conduction mechanism of $\mathrm{ZnO}$ and $\mathrm{ZnO}$ :Ni films deposited by atom beam sputtering, a technique, reported for the first time to grow $\mathrm{ZnO}$ based TCO film.

\section{4}

\section{Conclusion}

Polycrystalline $\mathrm{ZnO}$ and $\mathrm{ZnO}: \mathrm{Ni}$ films of thickness $\sim 80 \mathrm{~nm}$ are deposited by atom beam sputtering. Crystalline phases of the films and crystallite size are determined by grazing angle $\mathrm{X}$-ray diffraction. The present results reveal incorporation of $\mathrm{Ni}$ in the $\mathrm{ZnO}$ matrix, most probably at the $\mathrm{Zn}$ sites in $\mathrm{a}+2$ state. The resistivity of the $\mathrm{ZnO}: \mathrm{Ni}$ film $\left(\sim 9 \times 10^{-3} \Omega \mathrm{cm}\right)$ is found to be two orders of magnitude smaller as compared to pure $\mathrm{ZnO}$ film $(1 \Omega \mathrm{cm})$. Two important mechanisms reported in the literature viz. influence of $d-d$ transition bands and electron scattering from crystallites/grains are discussed as the possible causes for the increase in conductivity on $\mathrm{Ni}$ doping in $\mathrm{ZnO}$. The reduction in resistivity in the $\mathrm{Ni}$-doped $\mathrm{ZnO}$ film and an average transmission across the visible spectrum of $\sim 83 \%$ qualify this system to be an important candidate for TCO material.
ACKNOWLEDGEMENTS We are thankful to Indian Institute of Technology Delhi, Inter University Accelerator Centre, New Delhi and National Physical Laboratory; New Delhi for providing us experimental facilities. We are also thankful to Prof. S. Nozaki, Department of Electronic Engineering, The University of Electro-Communications, Japan for some useful discussions.

\section{REFERENCES}

1 C. Chen, F. Jen, Y.C. Lu, H.C. Wang, C.C. Yang, B.P. Zhang, Y. Segawa, Symp. N, ICMAT-2005, Singapore, July (2005)

2 S.H. Jeong, J.W. Lee, S.B. Lee, J.H. Boo, Thin Solid Films 435, 78 (2003)

3 J.J. Robbins, J. Harvey, J. Leaf, C. Fry, C.A. Wolden, Thin Solid Films 473, 35 (2005)

4 N. Sanmyo, Y. Tomita, K. Kobayashi, Key Eng. Mater. 248, 87 (2003)

5 H. Agura, A. Suzuki, T. Matsushita, T. Aoki, M. Okuda, Thin Solid Films 445, 263 (2003)

6 T. Minami, Semicond. Sci. Technol. 20, S35 (2005)

7 Z.-Z. Ye, J.-F. Tang, Appl. Opt. 28, 2817 (1989)

8 T. Wakano, N. Fujimura, Y. Morinaga, N. Abe, A. Ashida, T. Ito, Physica E 10, 260 (2001)

9 D.A. Schwartz, K.R. Kittilstved, D.R. Gamelin, Appl. Phys. Lett. 85, 1395 (2004)

10 P.V. Radovanovic, D.R. Gamelin, Phys. Rev. Lett. 91, 157202 (2003)

11 Z. Yin, N. Chen, F. Yang, S. Song, C. Chai, J. Zhong, H. Qian, K. Ibrahim, Solid Stat. Commun. 135, 430 (2005)

12 X.B. Wang, C. Song, D.M. Li, K.W. Geng, F. Zeng, F. Pan, Appl. Surf. Sci. 253, 1639 (2006)

13 D. Shimono, S. Tanaka, T. Torikai, T. Watari, M. Murano, J. Ceram. Proc. Res. 2, 184 (2001)

14 S. Singh, N. Rama, M.S. Ramachandra Rao, Appl. Phys. Lett. 88, 222111 (2006)

15 B.D. Culity, Elements of X-ray Diffraction (Addison-Wesley, Reading, MA, 1978), p. 102

16 B.D. Cullity, S.R. Stock, Elements of X-ray Diffraction (Prentice Hall, Englewood Cliffs, NJ, 2001), p. 194

17 A. Kuroyanagi, J. Appl. Phys. 66, 5492 (1989)

18 K.S. Kim, R.E. Davis, J. Electron. Spetrosc. Relat. Phenom. 1, 251 $(1972 / 1973)$

19 S. Hüfner, G.K. Wertheim, Phys. Rev. B 8, 4857 (1973)

20 G.H. Yu, L.R. Zeng, F.W. Zhu, C.L. Chai, W.Y. Lai, J. Appl. Phys. 90, 4039 (2001)

21 E. Burstein, Phys. Rev. 93, 632 (1954)

22 H. Katayama-Yoshida, K. Sato, Physica B 327, 337 (2003)

23 Y. Imai, A. Watanabe, J. Mater. Sci. Mater. Electron. 15, 743 (2004) 